\title{
Split vs. Single Bolus CT Urography: Comparison of Scan Time, Image Quality and Radiation Dose
}

\author{
Nicole Morrison, Sherrie Bryden and Andreu F. Costa * \\ Queen Elizabeth II Health Sciences Centre, Department of Diagnostic Radiology, Dalhousie University, Halifax, \\ NS B3H 2Y9, Canada; nc414248@dal.ca (N.M.); Sherrie.Bryden@nshealth.ca (S.B.) \\ * Correspondence: andreufcosta@gmail.com; Tel.: +1-902-473-5452
}

Citation: Morrison, N.; Bryden, S.; Costa, A.F. Split vs. Single Bolus CT Urography: Comparison of Scan Time, Image Quality and Radiation Dose. Tomography 2021, 7, 210-218. https://doi.org/10.3390/tomography 7020019

Academic Editor: Brian D. Ross

Received: 14 April 2021

Accepted: 18 May 2021

Published: 20 May 2021

Publisher's Note: MDPI stays neutral with regard to jurisdictional claims in published maps and institutional affiliations.

Copyright: (C) 2021 by the authors Licensee MDPI, Basel, Switzerland. This article is an open access article distributed under the terms and conditions of the Creative Commons Attribution (CC BY) license (https:/ / creativecommons.org/licenses/by/ $4.0 /)$.

\begin{abstract}
The purpose of this study was to compare the scan time, image quality and radiation dose of CT urograms (CTU) using a split vs. single bolus contrast media injection technique. A total of 241 consecutive CTUs performed between August 2019-February 2020 were retrospectively reviewed. There were three study groups: Group $1,<50$ years old, 50/80 cc split-bolus administered at 0 and $700 \mathrm{~s}$ post initiation of injection, with combined nephrographic and excretory phases; group $2, \geq 50$ years old, same split-bolus protocol; and group 3, $\geq 50$ years old, 130 cc single bolus injection, with nephrographic and excretory phases acquired at $100 \mathrm{~s}$ and $460 \mathrm{~s}$ post injection initiation. The recorded data elements were scan time, number of excretory phases, imaging quality based on opacification of the urinary collecting system $(<50 \%, 50-75 \%, 75-100 \%)$, and dose-length product (DLP). Associations between group and categorical variables were assessed (Chi-square); mean scan time and DLP were compared (one-way ANOVA). Following analysis, proportionally fewer CTUs required a repeat excretory phase in group $3(32 / 112,28.6 \%)$ than in groups $1(25 / 48,52.1 \%)$ and 2 $(37 / 80,46.3 \%)(p=0.006)$. Mean scan time was significantly lower in group $3(678 \mathrm{~s})$ than in groups 1 (1046s) and 2 (978 s) ( $p<0.0001)$. There was no association between groups and image quality $(p=0.13)$. DLP was higher in group $3(1422 \pm 837 \mathrm{mGy} \cdot \mathrm{cm})$ than in groups $1(1041 \pm 531 \mathrm{mGy} \cdot \mathrm{cm})$ and $2(1137 \pm 646 \mathrm{mGy} \cdot \mathrm{cm})(p=0.003)$. In conclusion, single bolus CTU resulted in significantly fewer repeat phases and faster scan time at the expense of a slightly higher radiation dose.
\end{abstract}

Keywords: computed tomography urography; hematuria; radiation dose; imaging quality; time analysis

\section{Introduction}

CT urography (CTU) is a valuable imaging examination for assessing a variety of conditions. The 2019 American College of Radiology (ACR) Appropriateness Criteria rate CTU as the first-line imaging examination for patients with microhematuria and risk factors for urologic malignancy, and no history to suggest a benign cause [1]. Similarly, the American Urological Association (AUA) recommends CTU in patients with asymptomatic microhematuria that persists after treatment or exclusion of any benign causes [2], and these guidelines have been endorsed by the American College of Physicians [3]. Additional indications for CTU include evaluation of patients with gross hematuria, for which the pre-test probability of malignancy is 30-40\% [1], staging and surveillance of patients with urinary tract malignancy, assessing for urinary tract injury or postsurgical integrity, congenital abnormalities, and urinary obstruction $[4,5]$.

Despite its widespread use, optimizing CTU technique is a challenge, and there is no consensus regarding a standard protocol [6]. The most common CTU technique acquires three separate phases or CT acquisitions at the following timepoints: An unenhanced phase prior to contrast media injection; a nephrographic phase acquired $80-120 \mathrm{~s}$ after intravenous (IV) injection of contrast media; and an excretory phase, acquired several minutes after contrast media injection, during which contrast media is excreted by the kidneys and opacifies the upper urinary tracts [6]. In this technique, the entire contrast 
media volume is injected as a single bolus; the advantage is that all of the contrast bolus contributes to the nephrographic and excretory phases, at the expense of three separate CT acquisitions, which results in higher ionizing radiation dose to the patient [6,7]. The second most common CTU technique is the split-bolus technique, where the nephrographic and excretory phases are acquired at the same time, in order to eliminate CT acquisition, and thereby, reduce the radiation dose by approximately one-third. Similar to the single-bolus technique, an unenhanced phase is first acquired. Then, the contrast media bolus is split into two injections. Approximately one-third of the bolus is injected several minutes prior to scanning; this portion of the bolus opacifies the urinary collecting system at the time of scanning. Approximately two-thirds of the bolus is injected 80-120 s prior to scanning; this portion of the bolus enables the kidneys to be imaged in the nephrographic phase, which corresponds to the phase when renal tumors are most evident on CT. Although the split bolus technique eliminates a third acquisition and reduces the amount of ionizing radiation, the disadvantage of splitting the bolus is that less contrast media contributes to enhancement of the kidneys and opacification of the urinary collecting system, which may degrade image quality.

Previously, our center used a split-bolus technique for CTU in all patients. However, we frequently encountered instances where the post-contrast phase did not opacify the entire upper urinary tract. These suboptimal CTUs were brought to the attention of the radiologist, who often requested a repeat acquisition to obtain better images in the excretory phase. Given that a repeat excretory phase eliminates the radiation-dose savings advantage of the split-bolus technique, we recently changed our protocol to a three-phase technique in patients $\geq 50$ years of age. This age cut-off was chosen to balance the increased pre-test probability of upper urinary tract malignancy and need for good imaging quality in older patients [8], vs. the risk of radiation, which is higher in younger adults [9]. The objectives of this study were to compare the scan time, imaging quality, and radiation dose of the single-bolus vs. the split bolus CTU techniques.

\section{Materials and Methods}

\subsection{Study Design}

This retrospective study was approved by our institutional research ethics board (REB) as a quality assessment study. The need for full REB review and patient consent was waived. A search of the Radiology Information System was performed to retrieve all outpatient CTU examinations performed at the Queen Elizabeth II Health Sciences Centre from 20 August 2019 to 29 February 2020. This corresponded to approximately 3 months before, and after, changing our CTU protocol on 20 November 2019. Any examinations that deviated from normal protocol, such as the inclusion of additional phases or extending the $\mathrm{z}$-axis range, or those degraded in imaging quality for other reasons such as patient motion or interstitial injection were excluded.

\subsection{CT Urography Technique}

CTUs were performed on three Siemens CT scanners: Definition AS+, Definition Flash and Somatom Sensation 64 (Siemens Healthineers, Erlangen, Germany). Technical parameters of the CTU technique were similar between scanners, including reference kilovoltage (100-120 kVp) and reference tube current-time product (170-190 mAs). Iterative reconstruction was available on the AS+ and Flash scanners (SAFIRE), and set to 3. For both the single and split bolus protocols, CTUs were performed with the patients in the supine position, and an initial pre-contrast phase was acquired to assess for urinary tract calculi. For the split-bolus protocol, an injection of 50 cc iohexol 350, followed by 150 cc of normal saline was injected at a rate of $3 \mathrm{cc}$ per second. At $10 \mathrm{~min}$ after initiating the injection, a second contrast bolus of $80 \mathrm{cc}$ iohexol 350 and $25 \mathrm{cc}$ saline was administered. The combined nephrographic and excretory phases were imaged at $100 \mathrm{~s}$ thereafter, corresponding to $700 \mathrm{~s}$ after initiating the first contrast media injection. For the three-phase protocol, $130 \mathrm{cc}$ iohexol 350 followed by 150 cc normal saline were injected at 3 cc per second. The kidneys were 
imaged in nephrographic phase $100 \mathrm{~s}$ after initiating the injection. The kidneys, ureters and urinary bladder were imaged in excretory phase $6 \mathrm{~min}$, thereafter, corresponding to $460 \mathrm{~s}$ after initiating the first contrast media injection.

\subsection{Data Collection}

Patient and CT data were collected primarily by a fourth-year radiological technology student (NM). Image quality evaluation data was validated by a board-certified, fellowshiptrained abdominal radiologist with 5 years of experience (AFC). The radiologist also applied the inclusion/exclusion criteria. For each CTU examination, the patient age, sex, date of examination, and CT scanner were recorded. The timestamps of the initial pre-contrast phase and final post-contrast phase were recorded, and the difference was taken as the total scan time. The number of post-contrast phases was recorded. For each post-contrast phase, opacification of the upper urinary tract (renal pelvicalyceal systems and ureters) was graded as follows: $<50 \% ; 50-75 \%$; and $75-100 \%$. The dose-length product (DLP) was recorded.

\subsection{Statistical Analysis}

Demographic information of the study cohort was calculated. The cohort was divided into the following three groups: patients $<50$ years old, all of whom were imaged with the split-bolus protocol; patients $\geq 50$ years old who were imaged with the split-bolus protocol before 20 November 2019; and patients $\geq 50$ years old who were imaged with the single-bolus protocol after 20 November 2019. Differences in scan time and DLP were assessed with one-way ANOVA, with the Tukey post hoc test for comparison between patient groups. Chi-square was used to assess for any association between patient group and sex distribution, number of excretory phases, and quality rating of excretory phases 1 and 2. Statistical analysis was performed using Prism version 8.4.1 (GraphPad Software Inc., La Jolla, CA, USA).

\section{Results}

A flowchart of the study cohort is provided as Figure 1. There were 245 CTUs performed during the study period. Three CTUs were excluded due to the pathologic processes causing poor opacification of the urinary collecting system (two bladder tumors and one colovesicular fistula). One CTU was excluded due to protocol deviation. Three CTUs were excluded from radiation dose analysis (one dose report missing, and two imaging scan length protocol deviations). One CTU was excluded from the scan time and imaging quality assessment as the patient became anxious during examination, and the CT was temporarily halted.

A summary of patient and CTU characteristics for each group is provided in Table 1, and examples of excretory phase volume-rendered images are provided from each group in Figures 2-4. There was no association between patient group and sex distribution $(p=0.48)$. There was no statistically significant difference in mean scan times for the split bolus groups: $17 \mathrm{~min}, 26 \mathrm{~s}$ for the $<50$ year-old group, and $16 \mathrm{~min}, 18 \mathrm{~s}$ for the $\geq 50$ year-old group $(p=0.22)$. The mean scan time for the single bolus group was $11 \mathrm{~min}, 18 \mathrm{~s}$, and this was significantly shorter than both split bolus groups ( $p<0.0001$ for both groups). 


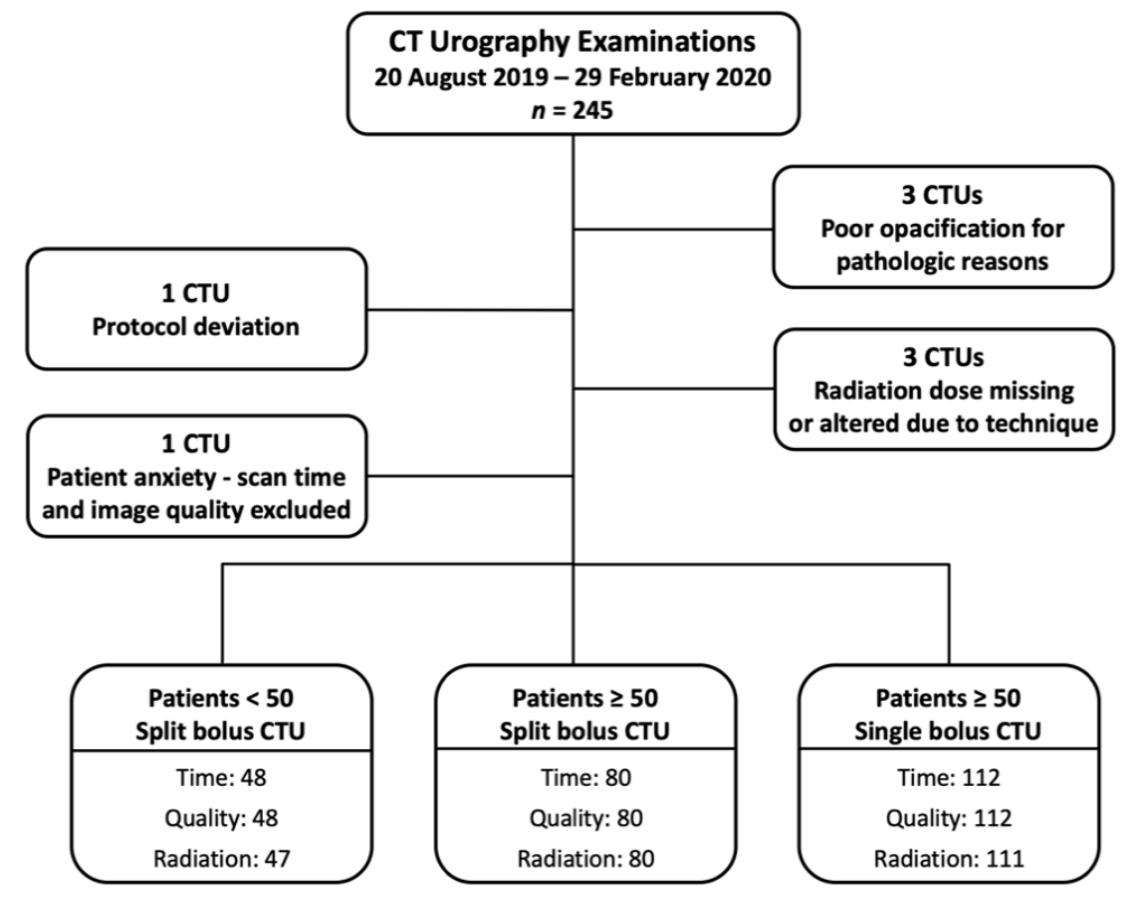

Figure 1. Study patient flowchart.

Table 1. Summary of patient and CT Urography characteristics for each patient group.

\begin{tabular}{|c|c|c|c|c|c|}
\hline Characteristic & $\begin{array}{l}\text { A: Split Bolus } \\
\text { Patients } \\
<50 \text { Years Old }\end{array}$ & $\begin{array}{l}\text { B: Split Bolus } \\
\text { Patients } \\
\geq 50 \text { Years Old }\end{array}$ & $\begin{array}{c}\text { C: Single } \\
\text { Bolus } \\
\text { Patients } \\
\geq 50 \text { Years Old }\end{array}$ & $\begin{array}{l}p \text {-Value } \\
\text { (One-Way } \\
\text { ANOVA) }\end{array}$ & $\begin{array}{c}p \text {-Value } \\
\text { (Tukey's Test) }\end{array}$ \\
\hline Age (years), mean \pm SD & $38.6 \pm 8.1$ & $68.6 \pm 10.1$ & $66.8 \pm 9.6$ & - & - \\
\hline $\begin{array}{c}\text { Sex } \\
\text { Male } \\
\text { Female }\end{array}$ & $\begin{array}{l}24 \\
24\end{array}$ & $\begin{array}{l}44 \\
36\end{array}$ & $\begin{array}{l}68 \\
45\end{array}$ & 0.48 & \\
\hline Total scan time (min:s), mean $\pm \mathrm{SD}$ & $17: 26 \pm 44$ & $16: 18 \pm 77$ & $11: 18 \pm 113$ & $<0.0001$ & $\begin{array}{c}\text { A:B } 0.22 \\
\mathrm{~A}: \mathrm{C}<0.0001 \\
\mathrm{~B}: \mathrm{C}<0.0001\end{array}$ \\
\hline $\begin{array}{c}\text { Number of excretory } \\
\text { phases acquired } \\
1 \\
\geq 2\end{array}$ & $\begin{array}{l}23 \\
25\end{array}$ & $\begin{array}{l}43 \\
37 \\
\end{array}$ & $\begin{array}{l}80 \\
32\end{array}$ & 0.006 & - \\
\hline $\begin{array}{c}\text { 1st excretory phase } \\
\text { contrast opacification } \\
<50 \% \\
50-75 \% \\
75-100 \%\end{array}$ & $\begin{array}{c}8 \\
14 \\
26\end{array}$ & $\begin{array}{l}12 \\
28 \\
40\end{array}$ & $\begin{array}{c}8 \\
30 \\
74\end{array}$ & 0.13 & - \\
\hline $\begin{array}{c}\text { 2nd excretory phase } \\
\text { contrast opacification } \\
<50 \% \\
50-75 \% \\
75-100 \%\end{array}$ & $\begin{array}{c}2 \\
9 \\
14\end{array}$ & $\begin{array}{c}8 \\
14 \\
15\end{array}$ & $\begin{array}{c}8 \\
13 \\
11\end{array}$ & 0.41 & - \\
\hline $\begin{array}{l}\text { Total dose-length product }(\mathrm{mGy} \cdot \mathrm{cm}) \\
\text { mean } \pm S D\end{array}$ & $1041 \pm 531$ & $1137 \pm 646$ & $1422 \pm 837$ & 0.003 & $\begin{array}{l}\text { A:B } 0.75 \\
A: C 0.008 \\
B: C 0.02\end{array}$ \\
\hline
\end{tabular}




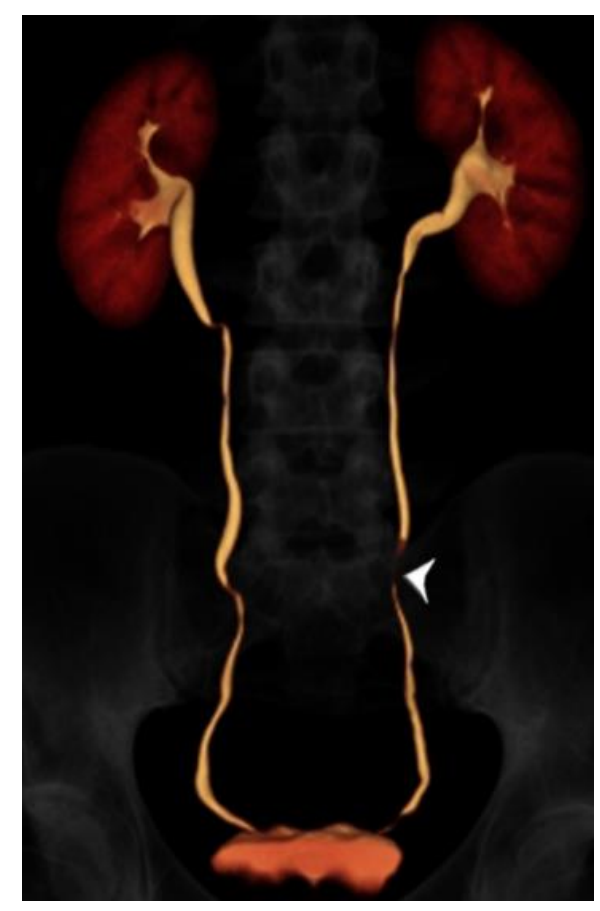

Figure 2. 24 year-old male with gross hematuria imaged with split-bolus CT urography. Volumerendered image of the excretory phase shows excellent opacification of the urinary collecting system. There is a very short region where the mid left ureter is not opacified by contrast (arrowhead). The total table time was $14 \mathrm{~min}$ and the dose-length product was $614 \mathrm{mGy} \cdot \mathrm{cm}$.

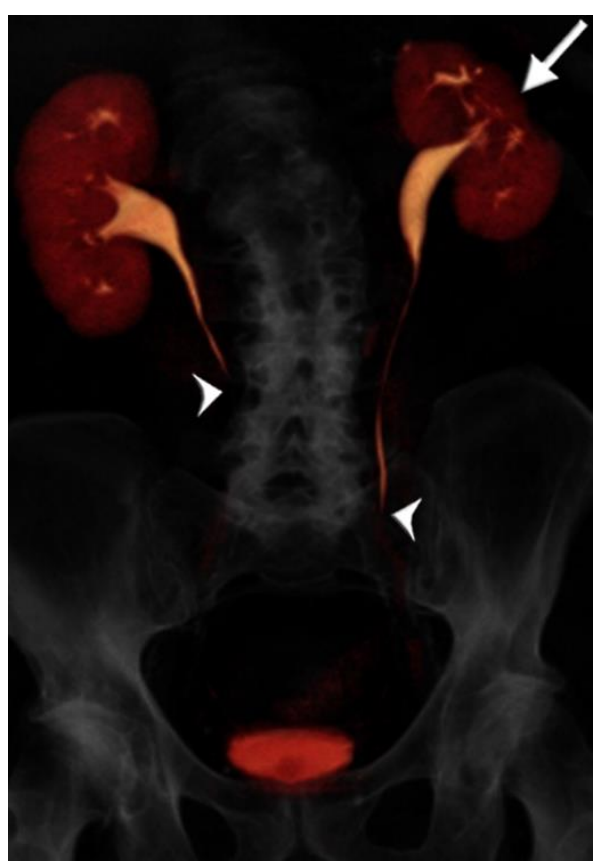

Figure 3. 73 year-old male with microhematuria imaged with split-bolus CT urography. Volumerendered image of the first excretory phase shows no contrast opacification of the mid-distal ureters (arrowheads). There is cortical scarring of the left kidney from previous nephrectomy for renal cell carcinoma (arrow). On repeat acquisition of the excretory phase, no improvement in image quality was achieved. The total table time was $17 \mathrm{~min}$ and the dose-length product was $1731 \mathrm{mGy} \cdot \mathrm{cm}$. 


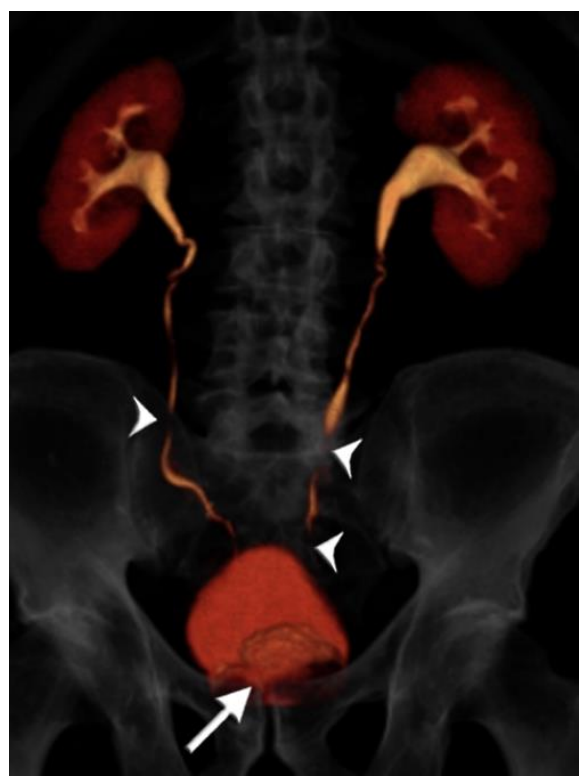

Figure 4. 75 year-old male with gross hematuria imaged with single-bolus CT urography. Volumerendered image of the excretory phase shows near complete contrast opacification of the ureters, apart from very short unopacified segments (arrowheads). There is an enlarged prostate indenting the urinary bladder base (arrow). There is no upstream hydroureteronephrosis and the image quality was deemed adequate. The total table time was $11 \mathrm{~min}$ and the dose-length product was $870 \mathrm{mGy} \cdot \mathrm{cm}$.

Table 1 shows the number of CTUs in each group that required additional excretory phases. Approximately half of CTUs in both split bolus groups required at least one additional excretory phase to opacify the collecting system: $25 / 48(52.1 \%)$ in the $<50$ year-old group and $37 / 80(46.3 \%)$ in the $\geq 50$ year-old group. In comparison, only $32 / 80(28.6 \%)$ CTUs in the single bolus group required at least one additional excretory phase, and this was significantly less $(p=0.006)$. In terms of imaging quality, the degree of urinary tract opacification in most CTUs was in the $75-100 \%$ range $(140 / 240,58.3 \%)$ in the first excretory phase. However, $70 / 240(30.0 \%)$ of CTUs were graded as $50-75 \%$ opacification, and $28 / 240(11.7 \%)$ of CTUs were graded as $<50 \%$ opacification. A total of $94 / 240$ (39.2\%) CTUs underwent a second excretory phase, and 7/240 (2.9\%) underwent a third excretory phase. For both the first and second excretory phases, there was no association between the 3 patient groups and opacification of the urinary collecting system ( $p=0.13$, and $p=0.41$, respectively).

The mean DLP values for the split bolus groups were not significantly different: $1041 \pm 531$ and $1137 \pm 646 \mathrm{mGy} \cdot \mathrm{cm}$ for the $<50$ and $\geq 50$ year-old groups, respectively $(p=0.75)$. The mean DLP of the single bolus group was $1422 \pm 837 \mathrm{mGy} \cdot \mathrm{cm}$, or $285 \mathrm{mGy} \cdot \mathrm{cm}$ higher than the corresponding $\geq 50$ year-old split bolus group. This was significantly higher than both the $\geq 50$ year-old $(p=0.02)$ and $<50$ year-old $(p=0.008)$ split bolus groups.

\section{Discussion}

In this study, we compared the scan time, image quality and radiation dose of split vs. single bolus contrast media injection techniques for CTU. The single bolus technique was on average 5-6 min more efficient than the split bolus groups. Whereas approximately half of patients imaged with the split bolus technique required a repeat excretory phasethereby eliminating the advantage in radiation dose savings-fewer than one-third of patients in the single bolus group required a repeat excretory phase. However, image quality was not significantly different between groups. The disadvantage of the single bolus group is a higher radiation dose: specifically, $25 \%$ more radiation $(285 \mathrm{mGy} \cdot \mathrm{cm})$ than the $\geq 50$ year-old split bolus group. To put this number into context, an abdominopelvic $\mathrm{CT}$ imparting $285 \mathrm{mGy} \cdot \mathrm{cm}$ to a 67 year old man (the mean age in our single bolus group) 
corresponds to an additional effective radiation dose of $5.13 \mathrm{mSv}$ and an increased cancer risk of $0.02 \%$ [10].

\subsection{CTU Technique - Comparison to the Literature}

Similar to our study, other authors have reported better contrast opacification of the urinary tract with the single bolus technique [11]. However, in another head-to-head study comparing a single-bolus three-phase technique to a split-bolus two-phase technique, Dillman et al. found that the single bolus technique yielded better distention of the urinary tract, but not better contrast opacification [12]. The split-bolus technique used by Dillman et al. was similar to the technique used in our study, with a similar delay of the combined nephrographic/excretory phase at around $12 \mathrm{~min}$ in both studies. However, in their protocol, slightly more intravenous saline was administered prior to the excretory phase ( $250 \mathrm{cc}$ vs. $150 \mathrm{cc}$ ) and more iodinated contrast media was administered for the excretory phase ( $22.5 \mathrm{mg}$ iodine vs. $17.5 \mathrm{mg}$ ). The $50-80 \mathrm{cc}$ split bolus ratio used in our study has been described elsewhere [11,13], and is similar to the 3:7 ratio that Lee et al. found yielded better renal cortical enhancement over a 1:1 split bolus ratio [14]. A minority of patients in our study demonstrated poor $(<50 \%)$ contrast opacification of the urinary tract: $8 / 48$ $(16.7 \%)$ in the $<50$ year-old split bolus group; $12 / 80$ (15.0\%) in the $\geq 50$ year-old split bolus group; and 8/112 (7.1\%) in the single-bolus group. These values are comparable to the $\sim 15 \%$ of patients with $<50 \%$ opacification in the split-bolus CTU study by Maheshwari et al. [13]. Based on the literature, it is clear that consistently opacifying the entire urinary tract at CTU remains a challenge. In addition to oral hydration and intravenous saline administration used in the CTU protocols in this study, other methods that have been proposed to improve image quality include changing patient position (such as log-rolling), abdominal compression, and the use of a diuretic [15-17].

\subsection{Radiation Dose of CTU}

It is important to consider the radiation dose imparted by CTU because it is routinely used to evaluate common conditions, such as asymptomatic microhematuria, but for which the prevalence of disease states (such as malignancy) which are causative is very low $[1,2,18]$. A recent study that modeled the risk of malignancy and associated mortality due to ionizing radiation from CTU found that, in a population of 100,000 patients with asymptomatic microscopic hematuria, there would be 53.1 and 478 patients diagnosed with upper tract urothelial carcinoma and renal cell carcinoma, respectively, but also 149 cases of radiation-induced malignancy and 101 fatalities [19]. The mean DLPs reported in our study compare favorably with what has been previously reported. For example, a recent study evaluating DLPs associated with CTU across 14 countries found a median of $1740 \mathrm{mGy} \cdot \mathrm{cm}$ and 25th and 75th percentiles of 869 and $2943 \mathrm{mGy} \cdot \mathrm{cm}$, respectively [15]. We limited the radiation dose in young patients by applying the split bolus protocol to patients $<50$ years old, which is similar to the 40-year old cutoff applied by Cheng et al. [7]. We also limited the radiation in young patients by having the radiologist check the unenhanced phase prior to contrast media injection, as hematuria in young patients is often caused by urinary tract calculi [20]. There is growing evidence that CTU can be safely avoided in younger patients presenting with hematuria, given that the prevalence of urologic malignancy in this population is almost negligible $[8,20,21]$. In fact, the European Society of Urogenital Radiology guideline for hematuria avoids CTU in patients $<40$ years old [22]; the AUA guidelines, in contrast, recommend CTU in all patients with asymptomatic microhematuria that persists after treatment or with no attributable benign cause [2].

\subsection{Is the Excretory Phase at CTU Necessary?}

Another important consideration with respect to CTU technique is whether the excretory phases with poor urinary tract opacification should be repeated, or whether an excretory phase should be acquired at all. There are two arguments against acquiring a uniformly opacified urinary collecting system. First, the prevalence of ureteral malignancy 
is very low: urothelial carcinoma of the bladder is 25 times more common than that of the kidney, and 100 times more common than urothelial carcinoma of the ureter [17]. Second, when present, ureteral malignancies are evident without the excretory phase. In a study of patients that underwent CTU prior to nephroureterectomy or ureteroscopy, all resected or biopsied tumors that were located in unopacified segments of the ureter were identifiable by secondary signs, without the need for repeat excretory phases [23]. Another study of 376 patients with hematuria and negative cystoscopy found that all subsequent urothelial carcinomas $(n=7)$ and renal cell carcinomas $(n=4)$ were evident in the nephrographic phase alone; the authors suggest that CTU protocols could be simplified by excluding the excretory phase altogether [24]. In other words, optimizing ureteral opacification in order to identify subtle ureteral carcinomas that are large enough to be seen on CTU, but not large enough to distend the ureteral lumen or cause hydronephrosis, may be entirely unnecessary, given the exceedingly low probability of such lesions [17].

\subsection{Limitations}

Our study has limitations. Although similar in technique to other centers, CTU protocols vary and our protocols and patient population are not necessarily generalizable to other centers. Data regarding patient weight or body mass index were unavailable, but patient girth influences the DLP of CT examinations with automated tube current and $\mathrm{kV}$ settings. A potential source of bias in our study is that different radiologists were asked whether a repeat excretory phase was warranted, which may have resulted in potential variability in how radiologists request repeat phases in patients with unopacified segments of the upper urinary tract.

\section{Conclusions}

In conclusion, we found that the single bolus CTU yielded fewer repeat excretory phases, similar imaging quality and faster scan time at the expense of a $25 \%$ higher radiation dose. Radiologists at our center find it easier to report the single bolus protocol, with dedicated nephrographic phase and fewer excretory phases. Similarly, our CT technologists prefer the more efficient scan time and improved patient throughput. Irrespective of technique, opportunities remain for improvement and standardization with respect to CTU imaging quality and radiation dose savings. There are also opportunities to improve evidence-based guidelines for work-up of conditions evaluated by CTU, such as hematuria.

Author Contributions: Conceptualization, A.F.C.; methodology, A.F.C.; validation, A.F.C.; formal analysis, A.F.C.; investigation, N.M., S.B. and A.F.C.; data curation, N.M., S.B. and A.F.C.; writingoriginal draft preparation, A.F.C.; writing-review and editing, N.M., S.B. and A.F.C.; supervision, A.F.C.; project administration, A.F.C. All authors have read and agreed to the published version of the manuscript.

Funding: This research received no external funding.

Institutional Review Board Statement: This study was approved by our institutional research ethics board as a quality improvement initiative. The need for full ethics board review and patient consent was waived. The study was conducted according to the guidelines of the Declaration of Helsinki, and was performed for the purposes of ensuring quality, evaluation, or standards of care under the oversight of the Nova Scotia Central Zone Diagnostic Imaging Quality Improvement and Safety Committee (16 April 2019).

Informed Consent Statement: Patient consent was waived by our institutional review board as a quality assurance study.

Data Availability Statement: Not applicable.

Acknowledgments: The authors thank Stephen Dingwall and Ahmed Almashharawi, Information Systems Technologists, for assistance with retrieving the patient cohort from the imaging database.

Conflicts of Interest: The authors declare no conflict of interest. 


\section{References}

1. Wolfman, D.; Marko, J.; Nikolaidis, P.; Khatri, G.; Dogra, V.; Ganeshan, D.; Goldfarb, S.; Gore, J.; Gupta, R.; Heilbrun, M.; et al. American College of Radiology Appropriateness Criteria Hematuria. Available online: https://acsearch.acr.org/docs/69490/ Narrative/ (accessed on 14 January 2020).

2. Davis, R.; Jones, J.S.; Barocas, D.A.; Castle, E.P.; Lang, E.K.; Leveillee, R.J.; Messing, E.M.; Miller, S.D.; Peterson, A.C.; Turk, T.M.; et al. Diagnosis, evaluation and follow-up of asymptomatic microhematuria (AMH) in adults: AUA guideline. J. Urol. 2012, 188, 2473-2481. [CrossRef] [PubMed]

3. Nielsen, M.; Qaseem, A. Hematuria as a Marker of Occult Urinary Tract Cancer: Advice for High-Value Care from the American College of Physicians. Ann. Intern. Med. 2016, 164, 488-497. [CrossRef]

4. Potenta, S.E.; D'Agostino, R.; Sternberg, K.M.; Tatsumi, K.; Perusse, K. CT Urography for Evaluation of the Ureter. Radiographics 2015, 35, 709-726. [CrossRef] [PubMed]

5. Silverman, S.G.; Leyendecker, J.R.; Amis, E.S., Jr. What is the current role of CT urography and MR urography in the evaluation of the urinary tract? Radiology 2009, 250, 309-323. [CrossRef]

6. Noorbakhsh, A.; Aganovic, L.; Vahdat, N.; Fazeli, S.; Chung, R.; Cassidy, F. What a difference a delay makes! CT urogram: A pictorial essay. Abdom. Radiol. 2019, 44, 3919-3934. [CrossRef]

7. Cheng, K.; Cassidy, F.; Aganovic, L.; Taddonio, M.; Vahdat, N. CT urography: How to optimize the technique. Abdom. Radiol. 2019, 44, 3786-3799. [CrossRef]

8. Lisanti, C.J.; Toffoli, T.J.; Stringer, M.T.; DeWitt, R.M.; Schwope, R.B. CT evaluation of the upper urinary tract in adults younger than 50 years with asymptomatic microscopic hematuria: Is IV contrast enhancement needed? Am. J. Roentgenol. 2014, 203, 615-619. [CrossRef]

9. Brenner, D.J.; Hall, E.J. Computed Tomography-An Increasing Source of Radiation Exposure. N. Engl. J. Med. 2007, 357, 2277-2284. [CrossRef]

10. Hanley, M.; Koonce, J.; Bradshaw, M. XrayRisk.com. Available online: https://www.xrayrisk.com/index.php (accessed on 29 April 2020).

11. Raman, S.P.; Fishman, E.K. Upper and Lower Tract Urothelial Imaging Using Computed Tomography Urography. Radiol. Clin. N. Am. 2017, 55, 225-241. [CrossRef]

12. Dillman, J.R.; Caoili, E.M.; Cohan, R.H.; Ellis, J.H.; Francis, I.R.; Nan, B.; Zhang, Y. Comparison of urinary tract distension and opacification using single-bolus 3-Phase vs split-bolus 2-phase multidetector row CT urography. J. Comput. Assist. Tomogr. 2007, 31, 750-757. [CrossRef] [PubMed]

13. Maheshwari, E.; O'Malley, M.E.; Ghai, S.; Staunton, M.; Massey, C. Split-bolus MDCT urography: Upper tract opacification and performance for upper tract tumors in patients with hematuria. Am. J. Roentgenol. 2010, 194, 453-458. [CrossRef] [PubMed]

14. Lee, D.; Cho, E.-S.; Kim, J.H.; Kim, Y.P.; Lee, H.-K.; Yu, J.-S.; Chung, J.-J. Optimization of Split-Bolus CT Urography: Effect of Differences in Allocation of Contrast Medium and Prolongation of Imaging Delay. Am. J. Roentgenol. 2017, 209, W10-W17. [CrossRef] [PubMed]

15. Gershan, V.; Homayounieh, F.; Singh, R.; Avramova-Cholakova, S.; Faj, D.; Georgiev, E.; Girjoaba, O.; Griciene, B.; Gruppetta, E.; Simonji, D.H.; et al. CT protocols and radiation doses for hematuria and urinary stones: Comparing practices in 20 countries. Eur. J. Radiol. 2020, 126, 108923. [CrossRef] [PubMed]

16. Renard-Penna, R.; Rocher, L.; Roy, C.; Andre, M.; Bellin, M.F.; Boulay, I.; Eiss, D.; Girouin, N.; Grenier, N.; Helenon, O.; et al. Imaging protocols for CT urography: Results of a consensus conference from the French Society of Genitourinary Imaging. Eur. Radiol. 2020, 30, 1387-1396. [CrossRef]

17. Shaish, H.; Newhouse, J.H. Split-bolus CT urogram: Is less more? Abdom. Radiol. 2017, 42, 2119-2126. [CrossRef] [PubMed]

18. Heller, M.T.; Tublin, M.E. In search of a consensus: Evaluation of the patient with hematuria in an era of cost containment. Am. J. Roentgenol. 2014, 202, 1179-1186. [CrossRef]

19. Yecies, T.; Bandari, J.; Fam, M.; Macleod, L.; Jacobs, B.; Davies, B. Risk of Radiation from Computerized Tomography Urography in the Evaluation of Asymptomatic Microscopic Hematuria. J. Urol. 2018, 200, 967-972. [CrossRef]

20. Lokken, R.P.; Sadow, C.A.; Silverman, S.G. Diagnostic yield of CT urography in the evaluation of young adults with hematuria. Am. J. Roentgenol. 2012, 198, 609-615. [CrossRef]

21. Fenwick, A.K.C.; Sala, E.; Canales, D.D. Prevalence of Urologic Disease Among Patients Investigated for Hematuria with CT Urography. Can. Assoc. Radiol. J. 2020, 72, 228-233. [CrossRef]

22. Van Der Molen, A.J.; Cowan, N.C.; Mueller-Lisse, U.G.; Nolte-Ernsting, C.C.; Takahashi, S.; Cohan, R.H. CT urography: Definition, indications and techniques. A guideline for clinical practice. Eur. Radiol. 2008, 18, 4-17. [CrossRef]

23. Hack, K.; Pinto, P.A.; Gollub, M.J. Targeted delayed scanning at CT urography: A worthwhile use of radiation? Radiology 2012, 265, 143-150. [CrossRef] [PubMed]

24. Rud, E.; Galtung, K.F.; Lauritzen, P.M.; Baco, E.; Flatabo, T.; Sandbaek, G. Examining the upper urinary tract in patients with hematuria-time to revise the CT urography protocol? Eur. Radiol. 2020, 30, 1664-1670. [CrossRef] [PubMed] 